\title{
POLÍTICAS NA EXTERIORIDADE - NOTAS SOBRE O EXÍLIO DE ESCRITORES LATINOAMERICANOS
}

\author{
Ana Brancher* \\ PPGHST/UFSC \\ Fábio Francisco Feltrin de Souza** \\ Doutorando PPGHST/UFSC
}

Resumo: $\mathrm{O}$ artigo analisa alguns escritores latinoamericanos obrigados a deixar seus países por perseguições políticas nos séculos XIX e XX. O exílio como imposição política é notadamente distinto da emigração, esta última geralmente decorrente de conjunturas econômicas mas também por opção pessoal. A condição de escritor exilado constituiu uma dupla exterioridade: Ao mesmo tempo em que interferiu na atuação política e na vida privada destes escritores, o exilio também influiu na respectiva produção e divulgação da literatura latinoamericana.

Palavras chave: Exílio; escritores; América Latina.

\section{Politics in exteriority - notes about Latin-American exile}

\begin{abstract}
The article analyzes some Latin American writers that were forced to leave their countries for politics persecutions during the $19^{\text {th }}$ and the $21^{\text {st }}$ century. The exile as a politic imposition is notoriously distinguished of emigration, this one usually resulting from economic circumstances and also personal choice. The condition of exiled writer established a double exteriority: at the same time that interfered in the politic performance and private life of these writers, the exile also influenced in the respective production and publicizing Latin-American literature.
\end{abstract}

Keywords: Exile; writers; Latin America.

Julio Cortázar, o renomado escritor argentino autor de Rayuela, prognosticou certa vez: "Virá o dia em que as histórias da literatura latinoamericana comportarão um capítulo exclusivamente dedicado à literatura do exílio". ${ }^{1}$ Cortázar bem sabia de onde e do que falava: Morando, por opção própria, em Paris desde 1951, ele vivenciou de forma intensa o exílio dos escritores latinoamericanos que, por diferentes trajetórias, fixaram-se na França nas décadas de 60, 70 e 80.

\footnotetext{
* Parte deste artigo é resultado do Pós-doutoramento realizado em 2007, na Université Paris X, Nanterre, com bolsa de estudos propiciada pela CAPES.

** Bolsista CAPES.
} 
Durante os séculos XIX e XX, boa parte dos países latinoamericanos passou por governos ditatoriais. Uma das primeiras providências que os governos ditatoriais adotaram foi silenciar as pessoas que faziam oposição política, seja através de prisões, submissões, exílios e, nos casos extremos mas não raros, através da morte. $\mathrm{O}$ silenciar as pessoas implicou também em eliminar projetos políticos e pessoais de gerações inteiras que se opunham a determinado governo. ${ }^{2}$ Todavia o recurso do exílio foi, como diz o adágio popular, uma faca de dois gumes, tanto para os governos quanto para os exilados.

Exilar, por definição, é expulsar da pátria. Mas não apenas da pátria, também das relações afetivas, dos pertencimentos cotidianos, das práticas culturais. Para Edward Said, o exílio é uma fratura incurável entre o ser humano e seu lar; para Giorgio Agamben, ele é "o exercício de uma vida nua" que transcende a uma relação jurídico-política marginal. Como imposição política, o exílio é notadamente distinto da emigração, esta geralmente decorrente de conjunturas econômicas mas também por opção pessoal. Um exemplo deste último caso, dentre os muitos, é o fato de inúmeros escritores, do mundo inteiro e em diferentes épocas, terem optado por viver em Paris simplesmente pelo clima intelectual que a cidade propiciava. ${ }^{3}$

Os itinerarios do exílio latinoamericano se deram principalmente para a Europa, Estados Unidos e Africa, mas também entre os próprios países latinoamericanos. Vários escritores argentinos da Geração de 1837 refugiaramse no Brasil, Chile e Uruguai fugindo das perseguições políticas; da mesma forma, escritores brasileiros refugiaram-se no Chile, Argentina, Uruguai durante governos ditatoriais entre as décadas de 1960 e 1980. Vale lembrar que a América Latina também foi terra de asilo. No século XX, por exemplo, exilados espanhóis, depois da Guerra Civil (1936-39), se refugiaram em Cuba, México, Chile, Brasil, Argentina; da mesma forma europeus que sofreram perseguição buscaram abrigo na América Latina, como foi o caso do escritor Stephan Zweig.

Fruto da condição de perseguidos políticos, uma rede de sociabilidades intelectuais foi se formando tanto no sentido de organização da resistência e combate quanto na discussão de correntes estéticas e difusão de obras literárias. Não é raro depoimentos de escritores hispanoamericanos que 'descobriram' o Brasil durante o exílio, e vice versa.

Trataremos de comentar a seguir, em dois movimentos distintos, alguns escritores latinoamericanos ${ }^{4}$ que foram obrigados a deixar seus países por perseguições políticas. 
Buenos Aires, primeira metade do século XIX. Junto à livraria de Marcos Sastre jovens letrados reuniam-se para trocar idéias, ler clássicos da filosofia iluminista, debater, escrever poemas, publicar artigos. Essa reunião de amigos foi nominada de Salón Literário. Era um fórum de debate, algo como um centro socializador de intelectuais que, de algum modo, comungavam de um horizonte semelhante de idéias. Um lugar onde questões do campo das artes, da cultura e da política eram discutidas, afirmadas e intercambiadas. A primeira aparição pública do grupo foi para proclamar a unidade entre as práticas política e literária e não apenas uma mera coexistência. Essa junção foi comum entre os românticos sulamericanos, contudo as práticas do governo de Juan Manoel de Rosas parecem ter potencializado essa imbricação, proporcionando a formação de várias sociedades de mesmo caráter, portadores de uma linha politizada mais ou menos comum. ${ }^{5}$

Após sua independência, a Argentina viveu um período de densos conflitos opondo o grupo dos unitários ao dos federalistas. Na prática observava-se um grande debate acerca do projeto de nação. Os unitários autodeclaravam-se 'civilizados' e estavam ligados à cidade de Buenos Aires. Já os federalistas receberam a alcunha de 'bárbaros', por parte do grupo rival, e estavam associados ao homem do campo, aos gauchos e aos caudilhos. ${ }^{6}$ Durante as décadas de 1830 e 1840 do século XIX, a Argentina estava sob o domínio do general Juan Manoel de Rosas. Ele foi governador da província de Buenos Aires. No entanto, uma série de acordos com políticos de outras províncias, como Facundo Quiroga, possibilitou que governasse toda a Argentina sem a caracterização de um governo central, como era desejo dos unitários.

Os românticos da geração de 1837, propunham inicialmente outra alternativa que fugisse da dicotomia unitários versus federalistas; entretanto, durante o segundo governo Rosas (1835 a 1852) esses mesmos escritores assumiram uma postura de frontal oposição e em alguns momentos unindo-se aos unitários, embora figuras como Juan Bautista Alberdi tenham esboçado uma frustrada aproximação com o general. ${ }^{7}$ Faziam parte desse grupo Esteban Echevería, Juan Maria Gutierrez, Domingos Faustino Sarmiento, Bartolomé Mitre, Vicente Fidel Lopez, José Marmól, Florêncio Varela, Mariquita Sánchez, Joana Manso, José Rivera Indarte e outros. A Escuela, como também era conhecido o grupo, preconizava a construção de um novo partido, um partido da nova geração, capaz de acabar com os antagonismos existentes entre unitários e federalistas e que também fosse alternativa à forma autocrática com a qual Rosas governava a Argentina. Nas palabras de Esteban Echeverría:

(...) la lógica de nuestra historia, está pidiendo la existencia de un partido nuevo, cuya misión es adoptar lo que hay de legítimo en uno o otro partido, y consagrarse en encontrar la solución pacífica de todos nuestros problemas sociales con la 
clave de una síntesis alta, más nacional y más completa que la suya, que satisfaciendo todas las necesidades legítimas, las abrace y las funda en una unidad. Ese partido nuevo no pueden representarlo sino las generaciones nuevas, y en concepto nuestro, nada útil harán por la patria, malgastarán su actividad, si no entran con decisión y perseverancia en la única gloriosa vía que les señale el rastro mismo de los sucesos de nuestra historia. ${ }^{8}$

Tanto o centralismo unitário quanto a proposição federalista carregavam signos e influências estrangeiras, foram posturas e ideais políticos importados do velho continente. Enquanto os primeiros praticamente reproduziam teorias européias, com nenhuma preocupação em modificá-las, os federalistas pareciam aceitar passivamente as condições dadas, também sem apresentar maiores propostas de alteração. Não havia, portanto, mediação entre os projetos e o ambiente em que agiam. ${ }^{9}$ Bernando Ricupero afirma que é possível identificar posturas tanto unitárias, quanto federalistas em processo de fusão ao longo da história argentina; contudo, quem poderia executar essa função seriam aqueles que "não tiveram vida pública e nem pertenceram a nenhum partido." ${ }^{10}$ Em outra palavras, Alberdi afirma que apenas sua geração, a nova geração argentina, tinha condições efetivas de construir uma moldura nacional e conduzi-la ao futuro. Herdeiros da tradição educativa dos tempos de Rivadavia, antes de agruparem-se junto ao Salón, a maioria dos integrantes da generación de 1837 estudou no Colegio de Ciencias Morales de Buenos Aires, instituição laica e estatal. Tiveram acesso, portanto, a toda uma tradição e literatura francesas. Quase todas as referências a outras literaturas eram mediadas pelas traduções francesas: Echeverría lia Byron em francês, Sarmiento citava Shakespeare em francês. Além disso, os recursos estilísticos, princípios literários, valores morais e políticos que armam sua noção de romantismo são provenientes da zona cultural francesa, como afirmou Vicente Fidel López em sua bibliografia ${ }^{11}$. A seleção de assuntos, problemas e tópicos importantes ao debate eram direcionadas, em parte, por uma cultura política permeada pela presença de discursos republicanos e por referências ao processo revolucionário vivido. Dessa forma, o romantismo político típico da região do Prata privilegiou, em grande medida, a esfera pública ${ }^{12}$. Membros da geração de 1837, como Alberdi, tinham isso bastante marcado. Em suas memórias ele escreveu que ao tomar a barca rumo ao exílio, sua vida privada havia deixado de existir ${ }^{13}$. Em muitos textos, seus companheiros definiam sua 'missão' como a de completar o plano intelectual dos revolucionários da geração anterior, da geração de Mayo. Muito próximos de Michelet e Mazzini, trataram a nação de maneira quase teológica e construíram para si o destino messiânico de sua concretização intelectual. Numa carta enviada a Alberdi e Gutiérrez, Echeverría considera que: 
La religión social de la Patria, la religión que nos legaron los heroicos promotores de su independencia y su libertad, esa religión que V.E. como todo patriota debe tener grabada en el fondo del corazón, pero que desgraciadamente unos han comprendido de un modo y otros de otro, es la religión que nosotros inculcamos como principio fecundo de concordia y fraternidad... Esa religión es Mayo. ${ }^{14}$

Como Rosas ordenou o fechamento do Salón, Echeverría, que nesse momento assumia uma postura de liderança, funda em 8 de julho de 1838, a secreta Asociación de Mayo (ou Jovem Argentina), numa clara alusão a Giovani Itália, criada por Giuseppe Mazzini em 1831. Nesse momento muitos italianos exilam-se no Brasil e no Uruguai. Luigi Rossetti, instalado no Brasil desde 1827, e Giovanni Battista Cuneo, eram os principais divulgadores das idéias de Mazzini entre os italianos residentes no Brasil, bem como entre os jovens da geração de $1837^{15}$. Esse era um momento de forte circulação de idéias, havia uma efervescência intelectual e revolucionária no ar. Contudo, tornou-se um tanto perigoso vivenciar esse clima na Confederação Argentina: o exílio foi uma das alternativas aos opositores de Rosas. ${ }^{16}$ A condição de ex-patriado marcou indelevelmente os escritos dessa geração. Em linhas lacrimosas esboçaram uma moldura para nação e se constituíram desde o exterior.

Jean-Luc Nancy aponta um paradoxo: nossa tradição, via de regra, coloca o exílio como uma desgraça; aliás, como a desgraça por excelência, aquela em que se pode reunir todas as dores. Por outro lado, também coloca o exílio como uma possibilidade positiva, de ser ou de existir. Caída ou partida, a desgraça é inevitável para a constituição do ser. ${ }^{17}$ Contudo, não se parte ou se cai de algum lugar; a topografia do ser (ou do saber) é a passagem, é o trânsito; é estar no entrelugar. Dito de outra maneira, o ser é o próprio centro no ir e vir, no sair e entrar. Heidegger já havia anunciado isso ao escrever sobre a ex-istencia, que nada mais é do que viver fora. Nancy aprofunda essa ponderação analisando apenas o prefixo ex (já que instância teria sido abandonada com a fragmentação do sujeito) para dizer que nossa existência é exilada. Dessa forma poderíamos afirmar que toda experiência de vida, de existir, é uma experiência de exílio, de estar na fronteira. Construímo-nos sob o signo do nomadismo, da perda, do sofrimento que toma muitas vezes as vestes do trauma. Para Freud o trauma é a repetição de uma vivência que será elaborada no confronto com a resistência implementada pelo sujeito. Nesse sentido não podemos confundir elaboração com recordação, uma vez que há no trauma uma dimensão do real, ainda que obscurecido pela recordação. Lendo Lacan, Paloma Vidal afirma que o real é o núcleo do trauma ao operar um (des)centramento do sujeito. A escrita do exílio se dá em torno desse trauma para construir uma trama ficcional afim de "romper a resistência da linguagem e escrever o real de uma história". ${ }^{18}$ 
Em Páginas Autobigraficas, compilação de cartas trocadas por Esteban Echeverría com outros exilados, o poeta escreve que:

Salir de su país violentamente, sin quererlo, sin haberlo pensado, sin más objeto que salvarse de las garras de la tiranía, dejado a su familia, a sus amigos bajo el poder de ella, y lo que es más, la Patria despedazada y ensangrentada por una gavilla de asesinos, es un verdadero suplicio, un tormento que nadie puede sentir, haberlo por sí mismo experimentado. $Y$ donde vamos cuando emigramos? No lo sabemos. A golpear puertas al extranjero; a pedirle hospitalidad, buscar unos patria en corazones que no pueden comprender la situación del nuestro, ni tampoco interesarse por un infortunio que desconocen y que miran tan remoto para ellos como la muerte. La emigración es la muerte: morimos para nuestros allegados, morimos para la Patria, puesto que nada podemos hacer por ellos. ${ }^{19}$

A escrita de Echeverría é marcada pelo trauma da expatriação, da emigração imposta. Pátria esta que se infla desde o exílio. Os contornos da nação não estavam muito bem definidos antes da deportação. Na verdade nunca estão, segundo Graciela Montaldo $^{20}$. Assim podemos dizer que não só a constituição de si é manejada na exterioridade, os discursos de nação, a teia de textualidades a congregar os retalhos que constituirão o real da nação, sua moldura homogeneizante, compõem-se desde fora. É de lá que as fronteiras e os contornos da guerra cultural definirão fronteiras, inimigos e identidades. Echeverría construiu-se como um herói romântico, um Ángel Caído ${ }^{21}$ disposto a enfrentar o 'mal', a barbárie em nome de uma 'missão', em nome da 'pátria':

Hablemos ahora del Ángel Caído. Sé que cuando esta segunda parte se publique, sublevará censuras de todo género, que en cada línea se encontrará una alusión maligna, una sátira. Nada me importa [...] El hombre que se siente con la fuerza de realizar una misión debe levantarse alto. ${ }^{22}$

Ele transformou a escrita em luta, em desterro seguro. Como seus contemporâneos europeus e americanos, sonhou o amanhã, sonhou a 'pátria' regenerada e livre das mãos daquele que por muitas vezes chamou de tirano e inimigo. E esse dia chegou: Rosas foi derrotado na batalha de Monte Caseros em 1852. Contudo, Echeverria morreu em 19 de fevereiro de 1851, e foi sepultado no cemitério da Matriz em Montevidéu. Porém este não foi seu último desterro. Seus restos se perderam em definitivo um ano mais tarde, após serem inexplicavelmente removidos. ${ }^{23}$ Ele está em lugar algum e em todas as partes. Está no entre-lugar.

Além de Echeverría, Mariquita Sanchez também encontrou seu desterro na escrita, na atividade intelectual, cultural e política. Encontrou a grandeza em sua 
própria vida. Seu diário e principalmente suas cartas constroem uma mulher forte, ilustrada e, melancolicamente, dramatizam sua condição duplamente exilada: fora do seu país em razão dos seus posicionamentos políticos e fora dos padrões do comportamento de mulher. Interlocutora dos jovens revolucionários, ganhava respeito e admiração, principalmente de amigos mais próximos como Gutiérrez. Mariquita Sanchez construiu uma auto-imagem e refletiu sobre a condição feminina. Na verdade, sobre a condição de mulher ilustrada num mundo dominado por homens. A cada palavra, a dor. A cada pausa, um suspiro enfraquecido de ser quem se é. Mas que renova as forças, renova a luta na mesma superfície desse ser:

Estoy cansada de lo que veo y sé. Quisiera ignorar todo, vivir en una choza abandonada al destino, y mi destino bizarro me pone siempre al corriente de tantas cosas que me afligen sin poderlas remediar. Mucho he envidiado las mujeres que no pasan de cierta altura, que no comprenden sino lo que pasa en la esfera donde tienen que vivir, para las, que mil goces fáciles de adquirir y que sospechan las penas que se sienten en otras. La elevación de las ideas ya sabes cuánto cuesta lo mejor que lee puede a uno suceder es que lo tomen por extravagante si es hombre y por pedante si es mujer ${ }^{24}$.

Nesse pequeno trecho percorrem signos da transgressão, da potência de ser além, de cruzar a zona fronteiriça da mulher simplesmente leitora. ${ }^{25}$ Narrar-se é um ato político. Esse tipo de escrita pode auxiliar a construir uma cultura de si e estabelecê-la como exercício de auto-reflexão. A capacidade de refletir sobre o que fazemos, em especial sobre o que fazemos de nós mesmos ou o que deixamos fazer conosco é atributo de uma certa condição humana e ela se dá pela linguagem como possibilidade de constante re-invenção do eu. A experiência da escrita é um exercício de transformação desse ser; através dela organizamos o pensamento, reafirmamos e transformamos conceitos. A escrita de Mariquita Sanchez ganha contornos de um desejo autobiográfico, de uma certa literatura de si. Ela tematizou sua existência, narrou seu drama de viver na fronteira, no limiar, no confim. Marcou politicamente sua geração ao afirma-se como ser pensante, como mulher ilustrada. Muitas mulheres miravam Mariquita Sanchez e a transformavam em inspiração. Sua coragem e bravura fascinaram algumas de suas contemporâneas. Pediam-lhe conselhos, opiniões. Manoela Gómez de Calzadilla, por exemplo, escreve a sua amiga lamentando-se das possibilidades proporcionadas à mulher:

Cuando yo recuerdo lo puedo que nos han enseñado, generalmente hablando, y observo a presente cuanto se he debilitado. La idea de hacernos progresar, me muero de pena, porque es para mi un principio, que las sociedades 
se ilustrarían mas pronto se el cultivo de la razón fuera simultáneo en ambos los sexos. (...) espero que cuando tengas um lugarcito me dês tu opinión sobre esto ${ }^{26}$.

A potência de ser, o ato político de Mariquita Sanchez no espaço belicoso da pluma, ganha um contorno binocular. Ela passa a ser a lente interpretativa de uma certa cotidianidade tensa e dramática. Sua opinião é definidora; uma bandeira. A escrita permite a transgressão, e como afirma Graciela Batticuore, reconstrói simbolicamente o lugar privilegiado na vida política; brinda o risco constante de viver e refletir sobre si na exterioridade.

Lendo Sarmiento, outro importante interlocutor de Mariquita Sanchez, Beatriz Sarlo chama atenção para o espaço privilegiado de condensação simbólica assumido pela escrita biográfica. A cada palavra, desenha-se uma arte de eleger não apenas acontecimentos, mas principalmente níveis narrativos capazes de organizar a construção de um sentido ${ }^{27}$. É de Maurice Blanchot, entretanto, a intervenção mais próxima à condição vivida por Mariquita Sanchez. Ao ler Kafka, Blanchot escreve nunca saber se estamos presos dentro da existência cotidiana (e nos voltamos desesperadamente para fora dela) ou se dela estamos excluídos (e por isso nela apoiamo-nos incondicionalmente ${ }^{28}$. Há uma fronteira, um limiar invisível e sempre deslocado entre o dentro e o fora, o sair e o entrar, a solidão e o anseio da comunidade. Kafka descreve essa fronteira como um exílio. Exílio que podemos associar ao duplamente experimentado por Mariquita Sanchez. Talvez não haja dois mundos como, cuidadosamente, sugere uma dada modernidade. Talvez nem exista um único. Talvez haja apenas o resíduo, o fora em seu escoamento eterno, como interpretou Peter Palbart ${ }^{29}$. Mariquita Sanchez viveu o fora e a errância ao exilar-se em si; ou melhor, ao refugiar-se, ao habitar, no sentido heideggeriano ${ }^{30}$, sua própria escrita. Em suas cartas há uma mulher múltipla que soube utilizar-se da condição de exilada política para construir-se. Soube o significado de deslizar nos limiares do existir. Suas palavras dançam e manejam aparições, criações de si. Criações estas bastante evidentes nas linhas de uma de suas cartas escrita em 1847, desde o Rio de Janeiro, onde permaneceu por pouco mais de um ano:

Aqui hago parte de la sociedad de cuerpo diplomático. Aqui hay lujo para quien quiere; pero puedes andar muy sencilla también. A mí tienen por francesa unos, otros por española, pero lo gracioso es que todos suponen que he estado en Europa por mis maneras. Yo les dejo crer. ${ }^{31}$ (Grifo nosso)

O velho continente era uma espécie de lugar quimérico para Mariquita Sanchez. Seus escritos evidenciam um desejo de Europa, uma vontade de ser. Desejo este partilhado por boa parte de sua geração: Alberdi dizia-se descendente de Cortéz, não de Montezuma ${ }^{32}$. Sarmiento escreveu que a Europa exercia seu 
dominio cultural sobre todas as partes do mundo, enquanto o resto vivia sob o signo da escravatura, da miséria, privado do verdadeiro esclarecimento. ${ }^{33}$ Diferente deles, Mariquita Sanchez não teve sua ida à Europa concretizada. O sonho de respirar os ares tão esperados permaneceu inconcluso. Mariquita Sanchez não deixava apenas as pessoas da corte brasileira acreditarem que era européia, ou que tenha estado por lá, talvez ela mesma tenha se convencido de tal fato. Na sombra da frase grifada podemos ler seu suspiro: "yo también creo". Seu lugar é, portanto, a soleira, o limiar dos entre-lugares.

A fronteira (o limiar da existência) é o lugar dos dramas humanos, onde a vida e a história acontecem. Para Giorgio Agamben, pensar a vida é pensar a fronteira da vida e por isso exílio e biopolítica seriam conceitos indissociáveis. ${ }^{34} \mathrm{O}$ filósofo italiano vai à antiguidade clássica e observa a problemática envolvida na decisão acerca do status jurídico do exílio: é o exercício do direito ou a imposição de uma penalidade? Agamben responde afirmando que o exílio é o exercício da vida nua, ${ }^{35} \mathrm{a}$ maneira de pertencimento ao estado de exceção ${ }^{36}$. Nesse sentido o exílio não é nem $\mathrm{o}$ direito, nem uma punição. $\mathrm{O}$ desterro pode ser chamado de bando, antigo termo germânico que designa tanto a exclusão da comunidade, quanto o ordenamento do soberano. Para Carl Schmitt, o soberano é aquele que está, ao mesmo tempo, dentro e fora do ordenamento jurídico, pois ele tem o poder de proclamar o estado de exceção, de suspender a validade da lei para que ela seja possível, para que se estabeleça o estado de direito. É porque ele pode suspendê-la que pode estabelecêla. ${ }^{37}$ Não podemos saber se o exilado está dentro ou fora da lei, já que ele existe no confim, no limiar, na fronteira da própria vida. ${ }^{38}$ Agamben, mostra-nos, pois, que o exílio não é uma relação jurídico-política marginal, o exílio é uma zona neutra de indiferença, entre o externo e o interno, entre exclusão e inclusão. Tanto a reflexão de Nancy, quanto a de Agamben, segundo Raul Antelo, afastarse-iam por completo da lógica trágica ou vitimizadora que parte da tradição moderna construiu para o exilado. $\mathrm{O}$ exílio é um asilo.

$$
* * *
$$

América Latina, segunda metade do século XX. Na conjuntura internacional da Guerra Fria, Argentina, Brasil, Chile, Paraguai e Uruguai foram sacudidos por movimentos políticos que resultaram em governos conduzidos por ditaduras civilmilitares. No Paraguai, um general tornou-se presidente em 1958 com um golpe de estado militar e foi reeleito por 8 mandatos consecutivos, desfrutando por 35 anos do mais longo governo militar na América Latina, no século XX. No Brasil, em 31 de março de 1964, os militares depuseram o chefe de estado e assumiram a presidência do país até 15 de março de 1985. No Chile, em 11 de setembro de 1973, o golpe militar também colocou na presidência um general que permaneceu até 1990. 
No Uruguai, um presidente civil deu um golpe de estado em seu próprio governo em 27 de junho de 1973, apoiado pelos militares que controlaram ou assumiram o poder até 1985. Em 24 de março de 1976 as Forças Armadas Argentinas assumem o Executivo depondo o então presidente, instalando governos militares até 1983. Esses golpes de Estado foram conduzidos por militares mas tiveram apoio civil das classes médias e, como comprovam estudos recentes, dos EUA. Via de regra, os governos dissolveram Parlamentos; proibiram e controlaram os partidos políticos, os sindicatos, as agremiações estudantis e algumas organizações sociais; alteraram Constituições; suprimiram as liberdades civis; estabeleceram censura na arte, na imprensa, nas Universidades. Os governos ditatoriais especializaram-se na censura, prisões, torturas e mortes. Para alguns, restou o exílio.

Foram na verdade milhares de professores, estudantes, operários, cineastas, sindicalistas, músicos, políticos forçados a deixar seus países. Estudos recentes constatam a dificuldade em aferir o número exato de exilados; trabalha-se com aproximações. ${ }^{39}$

A saída para o exílio não ocorreu da mesma maneira: houve aqueles que tiveram que deixar imediatamente seu país, muitas vezes sem sequer portar passaporte ou despedir-se de parentes; houve os que foram trocados a partir de sequestros; houve os que conseguiram de certa maneira organizar a partida, alguns mesmo já com perspectiva de trabalho no exterior, como foi o caso de alguns professores universitários. Também a chegada e instalação bem como a acolhida nos países de asilo se deu de maneira diferenciada, mas todos vivenciaram o deslocamento abrupto, a interrupção forçada. Um período imediato de estar lá e cá ao mesmo tempo. Segundo Leandro Konder, "Brecht, ele mesmo exilado, dizia que não há nada mais dialético do que a cabeça de quem vive no exilio. $\mathrm{O}$ exilado é obrigado o tempo todo a pensar no tempo. Suas certezas são filtradas pela dúvida. Seu destino não se decide. Quando acha que está familiarizado com o lugar para onde foi jogado, alguém ou algo à sua volta lhe lembra sua condição de 'estrangeiro"" 40 .

Apesar de trabalharem, por questões de sobrevivência, nos mais diferentes ofícios, para os escritores, por razões óbvias, a questão da língua foi determinante; no exercício de sua profissão, isto é, de escrever romances, por vezes o escritor experienciou de forma miuciosa o exercício de duas línguas, a do país de origem e a do país de adoção, o que exigiu um esforço a mais. No seu exílio em Berlim, o escritor chileno Antonio Skármeta escreveu, entre outras obras, No pasó nada, ${ }^{41}$ a lírica história de um adolescente filho de exilados, seus conflitos existenciais e políticos num país que ele não escolheu, onde não conhecia ninguém, não falava a língua. Skármeta foi obrigado a deixar o Chile em 1973 e só retornou 16 anos depois, em 1989. Para ele, 
Una cosa es escribir cuando se está en su país, donde la gente habla el mismo idioma y la cultura es familiar, y otra es ser escritor en el exilio. A pesar de todos los traumas que se originan en el exilio, que no sólo los he padecido sino que además he visto como el exilio ha quebrado y destrozado a mucha gente, debo decir que para un escritor alerta a su medio, el exilio es una experiencia que puede desembocar en la literatura -otorgándole a ésta valores dramáticos. ${ }^{42}$

Neste depoimento, inferimos a duplicidade do exílio, o fio tenue que limitou a possibilidade de vivenciá-lo como experiência ruim ou, pelo contrário, dele extrair a essência mesma para suas vidas e suas obras. Assim, para alguns escritores, o exílio foi uma experiência positiva pois tiveram a possibilidade de grande enriquecimento cultural com a descoberta de novos mundos, conhecer pessoas diferentes, outros países; todavia houve os que não se deram tão bem assim, que se suicidaram, que não se recuperaram, que fracassaram, que 'desistiram'; por seu lado, houve casos de em um mesmo autor o exílio proporcionar momentos bons e momentos amargos. Certamente o exílio foi mais complexo do que esta dualidade e implicou uma série de subjetividades que, tomadas coletivamente, acabaram por se tornar um fenômeno social. Um desses fenômenos pode se auferir no boom que a literatura latinoamericana teve nos anos 60, 70. Ao tempo em que foram forçados a viver em vários países, os escritores levaram sua ferramenta de trabalho, isto é, sua literatura; e uns mais outros menos, conviveram no mundo das letras dos diferentes países, mostrando suas obras e lendo as que circulavam, trabalhando em jornais, editoras. Não estamos afirmando que o grande sucesso que a literatura latinoamericana teve nos anos 60, 70 e 80 se deu em função do exílio dos escritores pois evidentemente houve os fatores editoriais/mercadológicos, a facilidade de impressão e de comunicação, o aumento das escolas decorrentes dos governos 'populistas' das décadas de 30 a 60 com o consequente aumento de leitores, etc ${ }^{43}$; consideramos simplesmente que o exílio colaborou para a divulgação da obra e dos próprios escritores - um dos gumes da faca.

Ao mesmo tempo em que influiu na produção literária, o exilio também interferiu na atuação política e na vida privada destes escritores. Podemos então inferir dois movimentos na interseção de exílio e literatura: a) a obra literária mesma, seja os romances que abordaram a questão do exílio ou os romances que resultaram da condição de exílio; b) como os escritores procuraram, no exílio, contribuir para que as ditaduras tivessem fim em seus países.

Entre os escritores exilados, evidentemente sem pretender enumerar todos $^{44}$, podemos referir os argentinos Julio Cortázar e Tununa Mercado; o brasileiro Tabajara Ruas; o já referido Antonio Skármeta; o paraguaio Augusto Roa Bastos; o uruguaio Mário Benedetti. 
A escritora argentina Tununa Mercado esteve exilada por duas vezes: entre 1967 e 1970, na França, onde ensinou literatura latinoamericana na Universidade de Besançon; e no México, entre 1974 e 1987. Entre seus livros estão Yo nunca te prometi la eternidad (2005), En Estado de Memória (1990) ${ }^{45}$. As obras abordam não só o exílio, mas a fuga, o medo cotidiano, o desespero frente ao autoritarismo, a perseguição, a guerra. Para Tununa, o exílio é violação permanente: "Desde el momento en que te vas de tu país lo maldecís, porque es como una mala madre que te echa. Y echa a los tuyos, a tus amigos; el mundo al que perteneces ya no está más. Es una violación permanente a tu intimidad y a la posibilidad de pensar y de crear".

Julio Cortázar ( 1914 - 1984$)^{46}$ trata do exílio em várias obras, notadamente em Rayuela (1963) e em Livro de Manuel (1974); neste último, temos um claro registro da necessidade, quase obrigação, que o escritor se impunha de denunciar as arbitrariedades dos governos ditatoriais. Falando a seu amigo Angel Rama sobre porque escreveu este livro, em carta datada de Paris em 9 de maio de 1973, Cortázar diz "...la intención era que el lector se adentrara en un territorio lo bastante fascinante desde el punto de vista novelesco (...) a fin de que el impacto de lo otro (documentación, denuncia de la tortura, defensa de lo que vós [Rama] y yo entendemos como único y legitimo camino revolucionario, sin perdas ontológicas) alcanzara el lector argentino y latinoamericano. ${ }^{~} 47$ De fato, Cortázar atinge este seu objetivo. Publicado na Argentina em 1974, o romance foi imediato sucesso de vendas: "La primera edición [de Libro de Manuel] de treinta mil ejemplares está agotada sin haber salido casi de Buenos Aires, y el libro se vende no solo en librerías sino en los kioscos de diarios. " 48 O romance trata de um grupo de exilados em Paris e como se organizam para viver e para combater a ditadura; entremeado a trama ficcional, o livro traz recortes de jornais, 'verdadeiros', tratando de práticas repressoras dos governos latinoamericanos. Alguns exemplos: na página 170, o livro reproduz recorte de um jornal francês que noticia Le coup d'etat en Argentine; nas páginas 364 e 383, informa o número e a atuação de militares de vários paises latinoamericanos treinados por militares estadunidenses e, citando a fonte, informa que entre 1964-1968 nada menos que 2259 militares brasileiros foram treinados por militares dos USA; na páginag 298, fala da morte de Carlos Lamarca; e traz vários relatos de torturas feitas pelos governos latinoamericanos. Seu romance é veemente. Mas Cortázar foi vigoroso também na 'prática': participou de Comitês para defesa dos presos políticos, organizou atos de protestos em frente a Embaixadas em Paris, organizou e participou de palestras e colóquios em Universidades européias; pressionou para que jornais franceses noticiassem o que se passava na América Latina: "Hay que insistir cotidianamente ante los periodistas para que sigan se ocupando de Chile y mantengan alerta la opinión. 
Tenemos el propósito de celebrar dentro de 2 o 3 meses una especie de Congreso Cultural destinado a denunciar los crímenes de la junta; ojalá podamos tener un gran eco internacional." 49 De maneira muito "concreta', ele procurou ajudar os que chegavam, se não hospedando, indicando onde morar, como proceder, conforme carta a Graciela de Sola, datada de Genebra, 14 de novembro de 1973: “... en Paris, ahora en Ginebra, hacemos todo lo posible para ayudar a los exiliados de Chile que empiezan a llegar por centenares." ${ }^{50}$ Ele participou do Tribunal Bertrand Russel, realizado em Roma, Bruxelas e Genebra que teve participaçãode vários escritores (o brasileiro Fernando Gabeira inclusive); participou Tribunal de Helsinque realizado no Mexico em fevereiro de 1975. Nestes tribunais registraramse numerosos testemunhos das torturas, prisões, assassinatos, privações dos direitos humanos que ocorriam na América Latina além da publicação de atas com os relatos e da divulgação na imprensa internacional destes fatos.

O escritor brasileiro Tabajara Ruas viveu no exílio entre 1971 e 1981; em Copenhage, escreveu $O$ amor de Pedro por João; nele retrata a trajetória (vivida por vários exilados brasileiros) de dois personagens que inicialmente vão para o Chile; após a queda de Allende em 1973, partem para o exílio na Europa onde vivem os paradoxos do exílio: ao mesmo tempo em que um incrível mundo se abria, também se apresentava distante pela condição de exilado, de estrangeiro. $A$ região submersa (1978) foi seu primeiro livro e foi escrito no exílio. Para Ruas, “(...)o exílio é algo que a gente procura esquecer, mas por outro lado tem que viver. Eu não me abati. Vi muita gente caindo em depressão, tentando se suicidar, muita gente desesperada, mas eu tratei de trabalhar, de aprender e de estudar. Terminei meu curso de Arquitetura e escrevi meu primeiro livro no exílio. Tratei de sobreviver". ${ }^{51}$

Um obra que fez enorme sucesso no Brasil foi $O$ crepúsculo do macho (1982), de Fernando Gabeira, exilado entre 1969 e 1979. Ainda que não seja considerada um romance (o autor a denomina relato), é o retrato cotidiano de um exilado, seus amores, seus amigos (a maioria estrangeiros), as dificuldades de um intelectual carioca que para sobreviver trabalha, entre outros oficios, como condutor de metrô.

Dos mais importantes escritores paraguaios, Augusto Roa Bastos (1917 - 2005), viveu no exílio entre 1947 e 1989, com algumas breves interrupções onde lhe foi permitido viver em seu país; a temática do exílio está presente ao longo de sua extensa obra, em vários contos e num de seus mais famosos romances Yo, El Supremo (1974). Particularmente o romance El Fiscal (1993) retrata como a condição do exílio atuou na subjetividade das pessoas; é o personagem que fala, mas podemos perceber como o escritor faz de sua própria experiência, enquanto sujeito degredado, uma prática discursiva : 
Sólo he tenido que tomar un nombre falso, despojar al yo de su imposible sinceridad, mudar de aspecto, inventarme nuevas señas particulares: espesa barba tornasolada por canas rubiáceas, una honda hendidura en el arco cigomático, y sobre todo, dominar perfectamente la lengua con el acento y la entonación de provincias. Aprendí a simular a la perfección la renguera del inválido y la parquedad silenciosa del que no quiere papar ni tragarse moscas, habida cuenta de que la renguera siempre inspira compasión y simpatía, dos elementos siempre útiles en la relación con el prójimo prepotente ${ }^{52}$

No exílio, Roa Bastos trabalhou como camareiro, vendedor ambulante, revisor, corretor de seguros, jornalista, professor universitário e, claro, como escritor:

El exilio fue una escuela permanente que me enseñó a ver las cosas con más seriedad. También significó dolor, como una muerte, un estado de duelo. Me tomó de cuatro a cinco años salir de la depresión no sólo psicológica, sino ontologicamente, recobrar mi dignidad como ser humano, que se había refugiado en las sombras. Me dediqué a escribir como un vehículo para recuperar mi condición humana, mi dignidad como persona. ${ }^{53}$

O escritor uruguaio Mario Benedetti viveu no exílio entre 1973 e 1983. Primavera con um esquina rota (1982) expressa o discurso do escritor exilado latinoamericano, como os acontecimentos políticos influenciaram nas relações pessoais; o protagonista está preso e sua mulher e filhas tiveram que exilar-se; no exílio ela reencontra um grande amigo do marido e ambos têm um envolvimento amoroso daí decorrendo toda uma trama existencial e política. ${ }^{54}$ Sobre os personagens e a trama, Benedetti diz ser baseado em fatos reais:

"En Primavera me pareció que la historia inventada, por referirse al cerrado circulo de una familia, podía dar una visión muy limitada del exilio uruguayo. Pienso que los capitulos denominados 'exilios'(todos basados en la realidad pero situados en muy distintos e distantes puntos de la diáspora) dan otra dimensión de esta colectividad dispersa. (...) también yo soy (o fui) un personaje en el exilio y de esa forma puedo narrar desde adentro experiencias vividas en esa emigración forzosa y frustránea. (...) Del exilio se vuelve cambiado, otra persona". ${ }^{55}$

Examinar o exilio de escritores latinoamericanos, assim como algumas de suas narrativas, nos permite perceber a sua especificidade nos cruzamentos culturais, políticos, sociais, históricos e existenciais em que eles se moveram 
em razão dos governos ditatoriais; a maneira como estes escritores viveram, interrogaram e refletiram em suas respectivas obras sua própria experiência do exílio nos permite compreender, obliquamente, um período histórico recente ainda com grandes dívidas historiográficas e que abarca vastas tessituras das sociedades latinoamericanas.

\section{NOTAS}

I "Le jour viendra où les histoires de la littérature latino-américaine comporteront un chapitre exclusivement consacré a la littérature de l'exil" apud FELL, C. "Dire l'exil trente ans après » in D'encre et d'exil 3 Troisième rencontres internationales des écritures de l'exil . Paris: BPI, 2003.

2 ROLLEMBERG, D.Exilio. Entre raizes e radares. Rio de Janeiro: Record, 1999. Nesta obra a autora faz minucioso estudo para o caso do Brasil.

3 Desde fins do século XVIII, a França representava a pátria de Revolução e da Liberdade. Para os escritores do mundo inteiro, ela sempre foi uma terra de asilo, que soube reconhecer genialidades incompreendidas. Foi lá que muitos deles se fizeram entender e entenderam seus países. Desde o irlandês James Joyce em ínícios do século XX até a iraniana Marjane Satrapi (nascida em 1970), milhares de escritores de todos os cantos do mundo escolheram, por uma ou outra razão, a França e particularmente Paris, como terra de asilo: do russo Vladimir Nabokov ao norte americano Henry James, do afegão Atik Rahimi ao chinês François Cheng, do haitiano René Depestre ao senegalês Leopold Senghor. Para os escritores latinoamericanos, não foi diferente. Do brasileiro Jorge Amado ao guatemalteco Miguel Angel Asturias, da argentina Marta Traba ao peruano Alfredo Bryce Echenique, centenas de escritores buscaram em Paris o espaço geo-político mas também o intelectual

4 Neste artigo, investigamos apenas escritores argentinos, brasileiros, chilenos, paraguaios e uruguaios. 5 MYERS, J. "Hacia la Conpleta Palingenesia y Civilización de las Nacionaes Americanas: Literatura Romantica y Projeto Social, 1830 - 1870". in: PIZARRO, A. (org). América Latina: Palavra, Literatura e Cultura - Emancipação do Discurso. vol II. São Paulo: Memorial, 1994, p. 231.

6 MYERS, op. cit.

$7 \mathrm{ld}$.

8 ECHEVERRÍA, E. Dogma Socialista. La Plata: Universidad de La Plata, 1940. Este texto foi primeiramente apresentado em 8 de julho de 1838 numa das atividades do Salón Literarío e mais tarde incorporado na redação final da obra Dogma Socialista redigida durante o exílio em Montevidéu e publicado no periódico El Iniciador.

9 RICUPERO, B. "As nações do romantismo argentino". In: PAMPLONA, M. A. e MÄDER, M. El. (orgs). Revoluções de independências e nacionalismos nas Américas. São Paulo: Paz e Terra, 2007, p. 228.

I0 ALBERDI, J. B.. Introdução. In: ECHEVERRIA, E. op. cit., p. 69.

I I TERÁN, Oscar. História de las ideas en Argentina: diez lecciones iniciales (1810 - 1980). Buenos Aires: Siglo Veintiuno Editores, 2008, p. 64.

12 ld, p 65.

13 ALBERDI, J. B. Escritos Póstumos: memorias y documentos. Buenos Aires: Imprensa, 1900, tomo XV.

14 ECHEVERÍA, E. Páginas autobiografias. Buenos Aires: EDUBA, 1962, . 85.

I 5 Rossetti e Cuneo escreveram para os jornais Giovani Itália, L'Italiano, II Legionario, El Iniciador e O Povo (Este último no Rio Grande do Sul). Tiveram intenso contato com os jovens da geração de 1837 e foram os principais responsáveis pela circulação das idéias de Mazzini entre eles. Num artigo publicado no dia I 5 de abril de 1838, Rossetti escreveu algo muito próximo do que Echeverría diria anos mais tarde conforme a nota anterior e meses antes do mesmo Echeverría fundar a Jovem Argentina: "Nosotros tenemos ya una Patria, que nadie podrá quitarnos jamás; pero ipodremos decir que tenemos libre e independiente el pensamiento? No, aún pesan sobre nosotros los restos de una educación material, falsa, retrograda, 
las preocupaciones, las necesidades, los descarrios de una edad bárbara. Nuestras costumbres, nuestras leyes, nuestra literatura lo justifican. [...]. No sereis libres en tanto que nuestra inteligencia permanezca esclava del error? La verdadera libertad es la Razón. La razón es el espíritu de Dios [...]."

I6 AMANTE, A. "Echeverría: entre dos reescrituras". In: Las Ranas: artes, ensayo y traducción. Año II, nº 2, abril de 2006.

I 7 NANCY, J-L. "La existência exilada". In: Revista Archipiélogo: cuardenos de crítica de la cultura. n 26-27, Madrid, 1996, p. 36.

I 8 VIDAL, P. A História em seus restos: Literatura e exílio no Conesul. São Paulo: Annablume, 2004.

19 ECHEVERÍA, E. Páginas autobiografias. Buenos Aires: EDUBA, 1962, p. 73 (hoja suelta).

20 MONTALDO, G. "Nación: una historia de la incultura". In: The Colorado Review of Hispanic Studies, vol. 5, Fall 2007, p. 39.

2I Nome de um dos poemas que Esteban Echeverría escreveu no exílio.

22 Carta de Esteban Echeverría a Melchor Pacheco y Obes. In: ECHEVERÍA, Esteban. Páginas autobiografias. Buenos Aires: EDUBA, 1962, p. 79.

23 KISNERMAN, N. Contribuición a la bibliografia de Esteban Echeverria: Buenos Aires: UBA, 1960.

24 SÁNCHEZ, M. Cartas, p. 40.

25 A educação feminina foi alvo de toda uma discursividade, de uma disciplina dos gostos, atitudes e saberes. Essa maquinaria discursiva construiu a imagem da mulher leitora, e apenas leitora, como a companheira ideal dos anti-rosistas. Essa era mulher dos novos tempos. Dessa forma, analfabetas e escritoras configuravam um perigo eminente à construção da nação civilizada. Cf. GRACIELA, B. "Cartas de mujer: cuadros de una encena borrada". In: IGLESIA, C. Letras y divisas: Ensayos sobre literatura y rosismo. Buenos Aires: EDUBA, 1998.

26 De Manuela Gómez Calzadilla a Mariquita Sanchez. Buenos Aires, 25/09/I84I, AZL. Apud. QUESADA, M. S. Mariquita Sánchez: Vida política e sentimental. Buenos Aires: Sudamericana, 1997.

27 SARLO, B. Escritos Sobre Literatura Argentina. Buenos Aires: Siglo XXI editores, 2007, p. 16.

28 BLANCHOT, M. O espaço literário. Rio de Janeiro: Rocco, 1987.

29 PELBART, P. P. “Literatura e Loucura”. In: RAGO, M. (org). Imagens de Foucult e Deleuze: ressonâncias nietzschianas. Rio de Janeiro: DP\&A Editora, 2002, p.287.

30 Habitar é construir e também cultivar. Significar deixar-ser, fazer surgir, proteger-se. É o existir na referências com as coisas, traço fundamental do que somos, saber do ser que somos.

3I SANCHÉZ, M. Cartas, 136.

32 É importante lembrar que para Alberdi "povoar é civilizar quando se faz com gente civilizada, isto é, com populações da Europa civilizada. Povoar, porém, não é civilizar, senão embrutecer, quando se povoa com chinos e indios da Ásia e negros da África. Povoar é empestar, corromper, degradar, envenenar um país, quando, em vez de servir-se da flor da população trabalhadora da Europa, se povoa com o lixo da Europa atrasada e menos culta”. Cf. ALBERDI, J. B. Bases y puntos de partida para La organización política de La República Argentina. Buenos Aires: Losada, 2004, p. 37.

33 SARMIENTO, D. F. Viajes. Buenos Aires: Belgrano, 198I, p. 135.

34 AGAMBEN, G. "Política del exilio" In Revista Archipiélago: cuadernos de crítica de la cultura. n 26-27, Madrid, 1996, p. 42.

35 A origem da expressão "vida nua" remonta a Walter Benjamin e seria a portadora do nexo entre violência e direito. Para Agamben, a relação entre política e vida é marcada pelo poder de decisão sobre o status da vida; a decisão que produz a vida nua. A vida nua é a vida apenas na sua dimensão biológica, marcada por ser apolítica e destituída de quaisquer direitos. Cf. AGAMBEN, G. Homo Sacer: O poder soberado e a vida nua I. Belo Horizonte: Humanitas, 2007.

36 Também recolhida de Walter Benajamin a expressão "estado de exceção" é pensado como um artifício do direito instituído em casos extremos, extraordinários, raros. Como o estado de sítio, por exemplo, num período em que a nação (ou estado) esteja passando por grandes dificuldades. Mas, segundo Agambem, o que era uma exceção passa a ser regra tornando a vida, uma vida nua; uma vida de abandono.

37 Cf. Ibidem.

38 ANTELO, R. op. cit. 
39 Para se ter uma idéia dos que tiveram que deixar seus países 'mais ou menos voluntariamente', colhemos os seguintes dados: Fanny Jediki estima que, no Chile, entre 500 mil e um milhão de chilenos deixaram o país entre 1973 e 1989; Maud Chirio estima que no Brasil, cerca de 300.000 deixaram o país após 1964; segundo Pablo Yankelevich e Silvina Jenses, cerca de 500 mil pessoas deixaram a Argentina entre 1950 e 1983. De todo modo, concordamos com Denise Rollemberg ao propor que quantificar o número de exilados redunda sempre em mera suposição pela falta de dados que possam ter um significado real.

40 Konder, L. Memórias de um intelectual comunista. Rio de Janeiro: Civilização Brasileira, 2008. pg. I 17 4I Skármeta, A. No paso nada. Buenos Aires: Sudamericana, 1980.

42 http://news.bbc.co.uk/hi/spanish/specials/newsid_|399000//3996|4.stm

43 Há farta bibliografia sobre a questão da explosão da literatura latinoamericana no período; para uma discussão recente, sugerimos BRAGANÇA, M. "Entre o boom e o pós-boom , dilemas de uma historiografia literária latinoamericana IN hhttp://www.revistaipotesi.uff.br/volumes/I 9/art I 0.pdf

44 Num levantamento ainda inconcluso, reuni os seguintes escritores exilados ao longo do século $X X$ : argentinos: Alicia Dujovne Ortiz, Alícia Kazamech, Antonio di Benedetto, Arnaldo Colveyra, Edgardo Cozarinski, Federico Undiano, Gregorio Manzur, Haroldo Conti, Hector Bianciotti, Juan Gelman, Juan José Saer, Julio Cortázar, Luisa Futuronski, Luiza Valenzuela, Manuel Puig, Mario Goloboff, Osvaldo Soriano, Rodolfo Rabanal, Saul Yurkievich, Tununa Mercado, ; brasileiros: Augusto Boal, Alfredo Sirkis, Darcy Ribeiro, Fernando Gabeira, Ferreira Gullar, Joel Rufino dos Santos, Jorge Amado, Reinaldo Guarany, Sarah Pinheiro de Las Casas, Tabajara Ruas; Walter Tenório Pontes; chilenos: Ana Vásquez, Antonio Skármeta, Ariel Dorfman, Leo Harare, Marcela Serrano, Michel Bonnefoy, Patricia Jerez, Roberto Bolaños; paraguaios: Augusto Roa Bastos, Rubén Bareiro Saguier; uruguaios: Fernando Ainsa, Leo Harari, Mario Benedetti. Para este levantamento inicial, adotei o critério de publicação de pelo menos um romance ou um livro de contos; destaco que não contemplei poetas e críticos literários, além de, naturalmente, outras categorias de exilados como cineastas, professores, políticos, pintores, jornalistas, músicos, etc.

45 MERCADO, T. Yo nunca te prometí la eternidad .Buenos Aires: Planeta, 2005. En Estado de memoria: Córdoba: Alcion, 1998.

46 Houve certa celeuma, datada, entre os argentinos, sobre a pertinência ou não de incluir Julio Cortázar entre 'os exilados'. Isto porque Cortázar decidira morar na França em 1951, aos 37 anos. Embora tenha voltado à Argentina algumas vezes, não voltou a residir no país. Libro de Manuel foi publicado pela primeira vez em 1974, em Buenos Aires pela Editorial Sudamericana.

47 Cartas (1969-1983). Madrid: Santillana, 2002. p. 1519.

48 Idem, p. 1520

49 Idem, p. 1554

50 Idem, p. 1539

5 I http://www.agenciacentralsul.org/index.php?option=com_content\&task=view\&id =932\&ltemid $=44$

52 BASTOS, A. R. El fiscal. Buenos Aires: Sudamericana, 1993. p. 14.

53 http://www.romanistik.uni-mainz.de/hisp/roa/La_realidad_superada.htm

54 BENEDETTI, M. Viento del exilio. Buenos Aires: Sudamericana, 2000; e Primavera con una esquina rota. Buenos Aires: Nueva Imagen, 1986.

55 http://www.radiohc.cu/espanol/sugerencias/sept06/Benedetti- I 8sept.htm 